\title{
Characterization of Carbonic Anhydrase IX Interactome Reveals Proteins Assisting Its Nuclear Localization in Hypoxic Cells
}

Pasquale Buanne, ${ }^{\dagger, \boldsymbol{\Delta}}$ Giovanni Renzone, ${ }^{\dagger, \boldsymbol{\Delta}}$ Francesca Monteleone, ${ }^{\dagger, \boldsymbol{\Delta}}$ Monica Vitale, ${ }^{\dagger, \S}$

Simona Maria Monti, " AnnaMaria Sandomenico," Corrado Garbi, ${ }^{\perp}$ Donatella Montanaro, ${ }^{\dagger}$ Marina Accardo," Giancarlo Troncone, ${ }^{\dagger, \nabla}$ Miriam Zatovicova, ${ }^{\bigcirc}$ Lucia Csaderova, ${ }^{\bigcirc}$ Claudiu T. Supuran, Silvia Pastorekova, ${ }^{\bigcirc}$ Andrea Scaloni, ${ }^{\ddagger}$ Giuseppina De Simone, ${ }^{*, \|}$ and Nicola Zambrano ${ }^{*}, \dagger, \S$

${ }^{\dagger}$ CEINGE Biotecnologie Avanzate SCaRL, Naples, Italy

${ }^{\ddagger}$ Proteomics and Mass Spectrometry Laboratory, ISPAAM, CNR, Naples, Italy

${ }^{\S}$ Dipartimento di Medicina Molecolare e Biotecnologie Mediche, Università di Napoli Federico II, Italy

"Istituto di Biostrutture e Bioimmagini, CNR, Naples, Italy

${ }^{\perp}$ Dipartimento di Biologia e Patologia Cellulare e Molecolare, Università di Napoli Federico II, Italy

\#Department of Public Health, Section of Pathology, Seconda Università di Napoli, Italy

${ }^{\nabla}$ Dipartimento di Scienze Biomorfologiche e Funzionali, Università di Napoli Federico II, Italy

ODepartment of Molecular Medicine, Institute of Virology, Slovak Academy of Sciences, Bratislava, Slovak Republic

Laboratorio di Chimica Bioinorganica, Università di Firenze, Italy

Supporting Information

ABSTRACT: Carbonic anhydrase IX (CA IX) is a transmembrane protein affecting $\mathrm{pH}$ regulation, cell migration/ invasion, and survival in hypoxic tumors. Although the pathways related to CA IX have begun to emerge, molecular partners mediating its functions remain largely unknown. Here we characterize the CA IX interactome in hypoxic HEK-293 cells. Most of the identified CA IX-binding partners contain the HEAT/ $A R M$ repeat domain and belong to the nuclear transport machinery. We show that the interaction with two of these proteins, namely XPO1 exportin and TNPO1 importin, occurs via the C-terminal region of CA IX and increases with protein phosphorylation. We also demonstrate that nuclear CA IX is enriched in hypoxic cells and is present in renal cell carcinoma

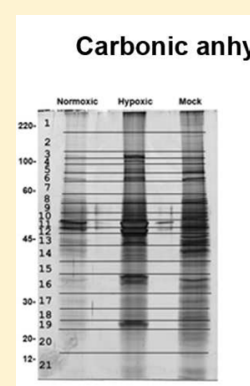

\section{Carbonic anhydrase IX interactome}
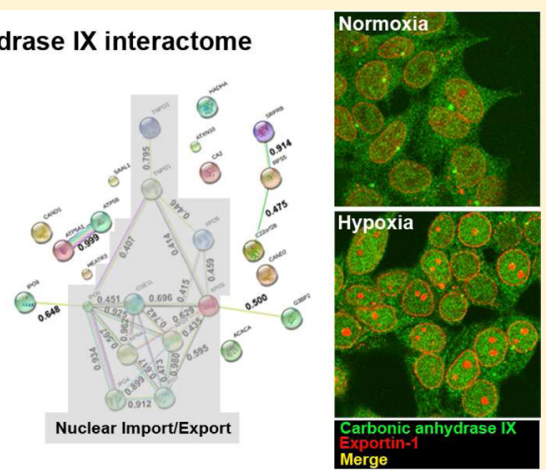
tissues. These data place CA IX among the cell-surface signal transducers undergoing nuclear translocation. Accordingly, CA IX interactome involves also CAND1, which participates in both gene transcription and assembly of SCF ubiquitin ligase complexes. It is noteworthy that down-regulation of CAND1 leads to decreased CA IX protein levels apparently via affecting its stability. Our findings provide the first evidence that CA IX interacts with proteins involved in nuclear/cytoplasmic transport, gene transcription, and protein stability, and suggest the existence of nuclear CA IX protein subpopulations with a potential intracellular function, distinct from the crucial CA IX role at the cell surface.

KEYWORDS: hypoxia, cancer, nuclear localization signal, nuclear export signal, HEAT repeat, ARM repeat

\section{INTRODUCTION}

Carbonic anhydrases (CAs, EC 4.2.1.1) are ubiquitous Znbinding enzymes acting as catalysts in the reversible hydration of $\mathrm{CO}_{2}$ to $\mathrm{HCO}_{3}^{-}$and $\mathrm{H}^{+}$. There are 15 human $\mathrm{CA}$ isoforms that differ in catalytic activity, subcellular localization, and tissue distribution. ${ }^{1}$ CA IX is a transmembrane, multidomain isoenzyme consisting of a $\mathrm{N}$-terminal proteoglycan (PG)-like region, a carbonic anhydrase catalytic domain, a transmembrane segment, and an intracellular (IC) tail. ${ }^{2,3}$ Biochemical characterization of CA IX demonstrated that it forms dimers through a symmetrical intermolecular disulfide bond involving C137 localized on the backbone of the catalytic domain. ${ }^{4}$ This study also showed that CA IX contains an intramolecular disulfide bond (C119-C299), a unique $N$-linked glycosylation site in the catalytic domain, and an O-linked glycosylation site next to the PG domain. The recently reported crystal structure of the CA domain of this enzyme confirmed its dimeric nature and enabled the proposal of a reliable model of the full-length protein, compatible with its known biological functions. ${ }^{5}$

Received: June 22, 2012

Published: November 26, 2012 
CA IX is a peculiar member of the CA family, also because of its tissue distribution. It is a tumor-associated protein, since it is expressed in limited amount within normal tissues (essentially in the gastrointestinal tract), whereas it is overexpressed on the surface of solid tumor cells, where it is linked with the hypoxic phenotype. Its expression is principally mediated by the HIF-1 transcription factor, ${ }^{6}$ and connected to a poor responsiveness to classical radio/chemotherapy. ${ }^{7}$ Several studies reported the functional involvement of $\mathrm{CA}$ IX in $\mathrm{pH}$ regulation, proliferation, adhesion/migration, and aggressiveness of tumor cells. $^{8-10}$ Thus, CA IX has been widely recognized as a valuable target for cancer diagnosis and treatment. ${ }^{1,11,12}$

A wealth of data report on the potential roles of the different CA IX domains. ${ }^{5,9,13}$ Catalytic CA domain has been implicated in the growth and survival of tumor cells, ${ }^{12}$ whereas PG domain has been related to cell adhesion and intercellular communication. ${ }^{14-16}$ The IC tail is essential for proper enzyme function and correct plasma membrane localization. Mutations of several residues in the submembrane IC region abolish both cell adhesion capacity and extracellular acidification potential. ${ }^{17}$ The IC tail contains three phosphorylation sites, namely $\mathrm{T} 443$, S448, and Y449; the first two modulate CA IX catalytic activity, while the latter is involved in EGFR-induced signal transduction to PI3/Akt kinase pathway. ${ }^{18,19}$

Altogether, these data highlight a very complex scenario, which contemplates multiple functions for each CA domain and may involve interactions with other protein partners. Nevertheless, except for earlier data on CA IX interaction with $\beta$-catenin ${ }^{14}$ and bicarbonate transporters, ${ }^{9}$ no systematic analysis has been performed to characterize protein complexes involving CA IX. Here, we report on the characterization of the human CA IX interactome. Our data unveils the protein machinery that assists CA IX stabilization and redistribution in nuclear compartments following hypoxic stimulation, and molecular targeting of which may have potential impact on future therapeutic developments.

\section{EXPERIMENTAL SECTION}

\section{DNA Constructs, Cell Lines, and Treatments}

The expression construct encoding the full-length CA IX protein was obtained by RT-PCR amplification of mRNA isolated from nonsmall cell lung cancer explanted tumors with ImProm-II Reverse transcriptase (Promega) and Pfu DNA polymerase. The primers for cDNA amplification were the following: ca9for, $5^{\prime}$-cacaagcttagccgccatggctccctgtgccccagc- $3^{\prime}$; ca9rev, 5'-cactctagattatcctcctcctttttgaactgcgggtggctccaggctccatctcggctacctc- $3^{\prime}$, synthesized at CEINGE oligonucleotide facility. The reverse primer contained additional bases for the incorporation of the Strep-tag II sequence, i.e., WSHPQFEK, into the final protein construct. The PCR product was cloned in the pRcCMV vector (Invitrogen). cDNA was fully sequenced for verification.

HEK-293, SH-SY5Y, and BJ5a cells were obtained from ATCC. HEK-293-CA9 cell line constitutively expressing the full-length human CA IX protein was obtained by stable transfection with pSG5C-CA9 plasmid. Cells were cultured in DMEM supplemented with $10 \%$ fetal bovine serum (Euroclone) and penicillin/streptomycin, at $37{ }^{\circ} \mathrm{C}$, in $5 \% \mathrm{CO}_{2}$ humidified atmosphere. HEK-293 cells were transfected with the empty pRcCMV vector, or with the Strep-tag CA IX vector by using the calcium phosphate method. $48 \mathrm{~h}$ after transfection, cells for hypoxic treatments were moved to an incubator with
$\mathrm{N}_{2}$ atmosphere containing $2 \% \mathrm{O}_{2}$ and $5 \% \mathrm{CO}_{2}$ for the last $16 \mathrm{~h}$. The shRNA-expressing plasmids sh2555 and sh2562 targeting CAND1 and the nonsilencing shNS construct were selected from a collection of constructs in the retroviral pSM2 vector (Open Biosystems). Cellular pools of HEK-293 clones were selected in the presence of puromycin $(2 \mu \mathrm{g} / \mathrm{mL})$ (Sigma) for two weeks. After selection, cells were propagated in the presence of culture medium containing puromycin $(0.25 \mu \mathrm{g} /$ $\mathrm{mL})$.

\section{Protein Extracts Preparation and Interactome Analysis}

Protein extracts were generated as already described. ${ }^{20}$ Each protein extract $(2 \mathrm{mg})$ was challenged with $250 \mu \mathrm{L}$ of Streptactin resin (IBA), and incubated for $12 \mathrm{~h}$, at $4{ }^{\circ} \mathrm{C}$. After washing, proteins were eluted with $100 \mathrm{mM}$ Tris- $\mathrm{HCl}, 150 \mathrm{mM}$ $\mathrm{NaCl}, 1 \mathrm{mM}$ EDTA, 0.1\% Triton X-100, 2 mM D-biotin, pH 8. Bound proteins from different cell preparations were analyzed by $12 \%$ SDS-PAGE $(14 \mathrm{~cm} \times 16 \mathrm{~cm} \times 0.75 \mathrm{~mm})$ in an SE600 vertical electrophoresis system (Hoefer), at $18{ }^{\circ} \mathrm{C}$, using a constant current setting of $25 \mathrm{~mA}$ and a maximum of $150 \mathrm{~V}$. All electrophoretic reagents were from BioRad. Proteins were visualized by silver nitrate staining. ${ }^{21}$ Digitalized gel images were acquired by using an Image Scanner III (GE Healthcare) apparatus and analyzed by the Image Master 2D Platinum 6.0 software (GE Healthcare), according to the manufacturer's instructions.

Independent lanes from SDS-PAGE were cut separately and each subdivided into 21 similar gel portions, which were then independently triturated, washed with water, in gel-reduced, Salkylated, and digested with trypsin (Sigma, sequencing grade) ${ }^{22}$ Resulting peptide mixtures were desalted by $\mu \mathrm{Zip}$ TipC18 (Millipore) using 50\% (v/v) acetonitrile, 5\% (v/v) formic acid as eluent. ${ }^{23}$

To isolate glycopeptides, digest aliquots from CA IXcontaining gel portion were solved in $80 \%(\mathrm{v} / \mathrm{v})$ acetonitrile, $2 \%(\mathrm{v} / \mathrm{v})$ formic acid and loaded on GELoader tips (Eppendorf, Germany), which were plugged with $3 \mathrm{M}$ Empore C8 extraction disk material (3 M Bioanalytical Technologies, $\mathrm{MN})$ and packed with ZIC-HILIC (200 $\mathrm{A}, 10 \mu \mathrm{m}$, zwitterionic sulfobetaine functional groups) resin (Sequant, Sweden). ${ }^{24}$ Loaded microcolumns were washed twice with $15 \mu \mathrm{L}$ of $80 \%$ (v/v) acetonitrile, $2 \%(\mathrm{v} / \mathrm{v})$ formic acid. Glycopeptides were first eluted with $10 \mu \mathrm{L}$ of $2 \%(\mathrm{v} / \mathrm{v})$ formic acid and then with 5 $\mu \mathrm{L}$ of $50 \%(\mathrm{v} / \mathrm{v})$ acetonitrile, $2 \%(\mathrm{v} / \mathrm{v})$ formic acid; pooled fractions were analyzed by MALDI-TOF-MS and nLC-ESILIT-MS/MS for PTMs characterization, as described below. All solvents were LC/MS grade (Baker). To confirm the nature of glycopeptides ( $\mathrm{N}$ - or O-linked), enriched peptide mixtures were deglycosylated by mixing $3 \mu \mathrm{L}$ of each sample solved in 50 $\mathrm{mM} \mathrm{NH}_{4} \mathrm{HCO}_{3}, \mathrm{pH} 8$, with $0.2 \mathrm{U}$ of PNGase $\mathrm{F}$ (Roche) solved in $2 \mu \mathrm{L}$ of the same buffer. ${ }^{25}$ Reaction mixtures were then incubated for $2 \mathrm{~h}$, at $37^{\circ} \mathrm{C}$, followed by addition of $1 \mu \mathrm{L}$ of $10 \%$ $(\mathrm{v} / \mathrm{v})$ formic acid. Peptide mixtures were eventually desalted on $\mu$ ZipTipC18 pipet tips (Millipore) before MALDI-TOF-MS and nLC-ESI-LIT-MS/MS analysis.

To isolate phosphopeptides, digest aliquots from CA IXcontaining gel portion were solved in $80 \%(\mathrm{v} / \mathrm{v})$ acetonitrile, $0.1 \%(\mathrm{v} / \mathrm{v})$ TFA, containing 2,5-dihydroxy-benzoic acid (20 $\mathrm{mg} / \mathrm{mL}$ ) and loaded on GELoader tips (Eppendorf, Germany), which were plugged with $3 \mathrm{M}$ Empore $\mathrm{C} 8$ extraction disk material (3 M Bioanalytical Technologies, MN) and packed with TitanSphere $\mathrm{TiO}_{2}$ resin $5 \mu \mathrm{m}$ (GL Science Inc., Japan). ${ }^{25}$ Loaded microcolumns were washed at first with $10 \mu \mathrm{L}$ of $80 \%$ 
(v/v) acetonitrile, $0.1 \%(\mathrm{v} / \mathrm{v})$ TFA, containing 2,5-dihydroxybenzoic acid $(20 \mathrm{mg} / \mathrm{mL})$, and then with $20 \mu \mathrm{L}$ of $80 \%(\mathrm{v} / \mathrm{v})$ acetonitrile, $0.1 \%(\mathrm{v} / \mathrm{v})$ TFA. Phosphopeptides were finally eluted with $10 \mu \mathrm{L}$ of $\mathrm{NH}_{4} \mathrm{OH}, \mathrm{pH} 10.5$, and directly analyzed by MALDI-TOF-MS and nLC-ESI-LIT-MS/MS, as described below.

Mass Spectrometry and Bioinformatic Analysis of the CA IX Interactome

Peptide digests were analyzed for protein identification by nLCESI-LIT-MS/MS, using an LTQ XL mass spectrometer (ThermoFisher) equipped with a Proxeon nanospray source connected to an Easy-nanoLC (Proxeon, Denmark). ${ }^{26}$ Peptide samples were separated on an Easy C18 column (100 mm $\times$ $0.075 \mathrm{~mm}, 3 \mu \mathrm{m}$ ) (Proxeon, Denmark). Mobile phases were $0.1 \%(\mathrm{v} / \mathrm{v})$ formic acid (solvent $\mathrm{A}$ ) and $0.1 \%(\mathrm{v} / \mathrm{v})$ formic acid in acetonitrile (solvent B), running at total flow rate of $300 \mathrm{~nL} /$ min. Linear gradient was initiated $20 \mathrm{~min}$ after sample loading; solvent B ramped from $5 \%$ to $35 \%$ over $45 \mathrm{~min}$, from $35 \%$ to $60 \%$ over $10 \mathrm{~min}$, and from $60 \%$ to $95 \%$ over $20 \mathrm{~min}$. Spectra were acquired in the range $\mathrm{m} / \mathrm{z} 400-2000$. Each sample was analyzed on the same LC column in duplicate under collisioninduced dissociation (CID)-MS/MS data acquisition conditions, enabling dynamic exclusion (repeat count 1 and exclusion duration $60 \mathrm{~s}$ ). Acquisition methods were the following: (i) data-dependent product ion scanning procedure over the three most abundant ions; (ii) as the previous method, with exclusion of the peptides confidently identified in the first run, in order to increase the number of identified peptides/ protein coverage. In both acquisition methods, mass isolation window and collision energy were set to $m / z 3$ and 35\%, respectively.

Raw data files from nLC-ESI-LIT-MS/MS experiments were searched by MASCOT search engine (version 2.2.06, Matrix Science, U.K.) within the Proteome Discoverer software package (Thermo Fisher, version $1.0 \mathrm{SP} 1$ ) against an updated UniProtKB nonredundant (2010/09/11) database containing 515203 sequence entries to identify proteins from gel slices. Database searching was performed by using Cys carbamidomethylation and Met oxidation as fixed and variable modifications, respectively, a mass tolerance value of $2.0 \mathrm{Da}$ for precursor ion and $0.8 \mathrm{Da}$ for MS/MS fragments, trypsin as proteolytic enzyme, and a missed cleavage maximum value of 2 . Other Proteome Discoverer parameters were kept as default. Candidates with at least 2 unique assigned peptides with an individual MASCOT score $>25$ (corresponding to an ion score above a confidence level of 95\%) were considered confidently identified. Definitive peptide assignment was always associated with manual spectra visualization and verification. Identification results from nLC-ESI-LIT-MS/MS analyses are reported in Supporting Information Table S1. Gel portions containing proteins with similar electrophoretic mobility are numbered from 1 to 21.

Enriched glycopeptide mixtures from CA IX-containing gel portions were loaded on a MALDI-TOF instrument target together with 2,5 -dihydroxy-benzoic acid $(10 \mathrm{mg} / \mathrm{mL})$ in $70 \%$ $(\mathrm{v} / \mathrm{v})$ acetonitrile, $0.06 \%(\mathrm{v} / \mathrm{v})$ trifluoroacetic acid, as matrix, by using the dried droplet technique. Samples were analyzed with a Voyager-DE PRO spectrometer (Applera), operating with a $337 \mathrm{~nm}$ laser. ${ }^{23,25,26}$ Mass spectra were acquired in positive polarity, using the instrument in linear mode. Internal mass calibration was performed with peptides from CA IX autoproteolysis. MALDI data were elaborated using the
DataExplorer 5.1 software (Applera). Enriched glycopeptide mixtures were also analyzed by nLC-ESI-LIT-MS/MS, as described above for protein identification.

MALDI-TOF spectra were assigned by using the GPMAW 4.23 software (Lighthouse Data, Denmark). This software generated a mass/fragment database output, based on CA IX sequence, protease selectivity, nature of the amino acid susceptible to eventual PTMs, and molecular mass of the modifying groups. Mass signals were matched to CA IX regions by using a mass tolerance value of $0.02 \%$. PTMs assignment was confirmed by additional nLC-ESI-LIT-MS/MS experiments and MALDI-TOF-MS analysis on CA IX samples subjected to PNGase F treatment.

Functional interaction analysis between the proteins identified by nLC-ESI-LIT-MS/MS was performed using the String v. 9.0 database (http://string-db.org/). ${ }^{27}$ Gene ontology classification of the identified proteins was performed through the web-accessible DAVID (v 6.7) annotation system (http:// david.abcc.ncifcrf.gov/home.jsp). ${ }^{28,29}$

Antibodies, Interaction Assays, and Western Blot Analysis

Antibodies used in this study were the following: CA IX VII/20 and M75 mouse monoclonals; ${ }^{30}$ CA IX (H-120, Santa Cruz Biotechnology) rabbit polyclonal; XPO1 (CRM1 C-20, Santa Cruz Biotechnology), goat polyclonal; TNPO1 (karyopherin $\beta 2$ F-6, Santa Cruz Biotechnology), mouse monoclonal; CAND1 (TIP120A 48, Santa Cruz Biotechnology), mouse monoclonal.

Coprecipitation experiments were performed on protein lysates $(1 \mathrm{mg})$ on Strep-tactin resin for $2 \mathrm{~h}$, at $4{ }^{\circ} \mathrm{C}$. Samples were washed 5 times with lysis buffer, and analyzed by $10 \%$ SDS-PAGE. Pull-down assays were performed with synthetic peptides as obtained by solid phase synthesis following standard Fmoc chemistry protocols ${ }^{31}$ and purified by reversed-phase LC on an ONYX monolithic C18 column (100 $\mu \mathrm{m} \times 10 \mu \mathrm{m}$ i.d,). Peptides ( $0.5 \mathrm{nmol}$ each) were bound to $10 \mu \mathrm{L}$ of Strep-tactin resin; binding reactions with protein cell lysates $\left(500 \mu \mathrm{g}\right.$ each) were performed at $4{ }^{\circ} \mathrm{C}$, followed by washes in lysis buffer, elution, and analysis by Western blots from 10\% SDS-PAGE. After blotting on PVDF membranes (Millipore), filters were probed with the XPO1, TNPO1, and CAND1 antibodies, as needed. Co-immunoprecipitation analysis of endogenous proteins was carried out on protein lysates $(3 \mathrm{mg}$ ) with anti-CA IX antibody VII/20 for $16 \mathrm{~h}$, at 4 ${ }^{\circ} \mathrm{C}$. Protein A/G plus agarose (Santa Cruz Biotechnology) was used to capture immunocomplexes. The latter were washed 5 times with lysis buffer, and analyzed by $10 \%$ SDS-PAGE.

Immunofluorescence Analysis and Immunohistochemistry

Cells for immunofluorescence were grown on glass slides, fixed with $3 \%(\mathrm{w} / \mathrm{v})$ paraformaldehyde, $1 \%(\mathrm{w} / \mathrm{v})$ sucrose in PBS for $15 \mathrm{~min}$, and permeabilized with $0.3 \%(\mathrm{w} / \mathrm{v})$ Triton X-100 in PBS for $3 \mathrm{~min}$, at $4{ }^{\circ} \mathrm{C}$. Incubations were performed with appropriate dilutions of the primary antibodies (CA IX, mouse monoclonal VII-20; XPO1, goat polyclonal). The secondary antibodies (Texas Red-conjugated donkey antigoat; Alexa-488conjugated donkey antimouse, Jackson Laboratories) were incubated for $1 \mathrm{~h}$, at $25^{\circ} \mathrm{C}$. The slides were observed on a Zeiss LM510 confocal microscope. For immunofluorescence analysis on isolated nuclei, HEK-293-CA9 cells were resuspended in $0.1 \%$ Tween-20 in PBS and spun at $13000 \times g$ for 15 min, at 4 ${ }^{\circ} \mathrm{C}$. The pellet was washed twice in PBS, and the isolated nuclei were fixed on polylysine slides (Thermo Scientific) with icecold methanol, and used for immunofluorescence with anti-CA 
IX antibody VII/20, followed by Alexa Fluor 488 donkey antimouse IgG (Invitrogen). Finally, the nuclei were stained with DAPI and analyzed by the Zeiss LSM510 laser scanning confocal microscopy.

For immunohistochemical analysis, $5 \mu \mathrm{m}$-thick sections were cut from archived formalin-fixed tissue blocks, dewaxed, and rehydrated with graded ethanol concentrations. Before staining, sections were incubated in citrate buffer $\mathrm{pH} \mathrm{6,} \mathrm{for} 45 \mathrm{~min}$, at 97 ${ }^{\circ} \mathrm{C}$, and endogenous peroxidase activity was blocked in $3 \%$ $\mathrm{H}_{2} \mathrm{O}_{2} /$ methanol for $10 \mathrm{~min}$. Nonspecific sites were blocked by background reducing components (DAKO), for $30 \mathrm{~min}$, at room temperature. Tissue sections were incubated at room temperature with primary antibody (CA IX H-120) at 1:50 dilution, for $1 \mathrm{~h}$. Staining was performed with LSAB+SystemHRP (DAKO) and diaminobenzidine chromogen (DAKO). Tissue sections were counterstained with Mayer's hematoxylin and coverslipped.

\section{RESULTS}

\section{CA IX Protein in Normoxic and Hypoxic HEK-293 Cells}

To capture possible interacting partners of human CA IX, a sequence encoding the C-terminal Strep-tag was fused to the full-length human CA IX cDNA. The tagged CA IX, overexpressed in normoxic HEK-293 cells, produced the typical two bands profile in SDS-PAGE (Figure 1A, lane 1). ${ }^{4}$ Identical CA IX pattern was present in transfected cells subjected to hypoxia (Figure 1A, lane 2), with a significant up-regulation of both protein components. Transfected cells were also stained with anti-CA IX antibodies and analyzed by confocal immunofluorescence microscopy. The Strep-tagged CA IX protein was clearly present at the plasma membrane of normoxic and hypoxic HEK-293 cells (Figure 1B). Intracellular and a diffuse nuclear signals were also observed both in control cells expressing low CA IX levels and in transfected cells overexpressing CA IX. Diffuse nuclear staining was interrupted at the nucleoli. A more pronounced staining was visible in hypoxic cells, in agreement with the higher protein expression levels. In this case, a similar pattern of subcellular distribution was observed, although nuclear and perinuclear staining was more abundantly represented, and nucleolar exclusion was decreased.

Tagged CA IX from transfected cells grown under normoxic or hypoxic conditions was copurified with bound interactors on Strep-tactin columns. Figure 1C shows the corresponding SDSPAGE after silver staining. Extracts from mock-transfected cells were also loaded on the column to identify the nonspecifically bound proteins (data not shown). nLC-ESI-LIT-MS/MS- and MALDI-TOF-MS-based peptide mapping experiments were performed to confirm the correct structure of the ectopically expressed CA IX protein (arrows in Figure 1C). They provided evidence of the expected processing at protein $\mathrm{N}$ - and Cterminus (93\% sequence coverage). Since CA IX is known to present glycosylated and phosphorylated amino acids, ${ }^{4,18}$ dedicated enrichment procedures for glycopeptides and phosphopeptides were used. ${ }^{25}$ However, MALDI-TOF-MS and nLC-ESI-LIT-MS/MS spectra revealed no signals related to phosphorylated peptides in eluted fractions from $\mathrm{TiO}_{2}$ resin. Conversely, clear signals associated with glycopeptides were observed within MALDI-TOF mass spectra of eluted fractions from HILIC resin (Supporting Information Figure S1), which allowed defining the expected occurrence of $\mathrm{N}$ - and $\mathrm{O}$ glycosylation at N309 and T78, respectively. ${ }^{4}$ Signal assignment

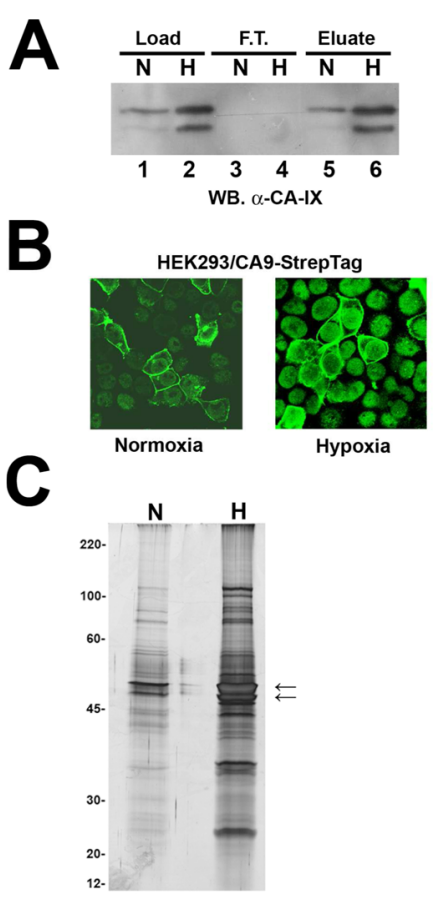

Figure 1. Ectopic expression of CA IX and SDS-PAGE analysis of the CA IX interacting proteins in HEK-293 cells. (A) Western blot analysis of lysates from normoxic (N) and hypoxic (H) HEK-293 cells transfected with the Strep-tagged CA IX vector. Protein extracts of lanes 1 and 2 were loaded on Strep-tactin columns for copurification of CA IX and its interactors in both normoxic and hypoxic conditions. Flow-through (lanes 3-4) and eluate (lanes 5-6) fractions were probed with a CA IX antibody. (B) Immunofluorescence analysis of CA IX in normoxic (left) and hypoxic (right) HEK-293 cells transfected with the Strep-tagged CA IX vector. (C) HEK-293 proteins copurified with Strep-tagged CA IX in normoxic and hypoxic cells were separated by SDS-PAGE and visualized by silver nitrate staining. Protein mixtures from normoxic and hypoxic, mocktransfected cells, were used as the subtraction lane. After staining, each of the three lanes was cut in 21 slices for protein identification by nLC-ESI-LIT-MS/MS analysis.

to glycopeptides was definitively demonstrated by independent nLC-ESI-LIT-MS/MS experiments. Since both analyses were performed on nonfractioned peptide mixture and in positive polarity, no eventual signals previously associated with negatively charged glycopeptides were detected. ${ }^{4}$

CA IX Interactome in Normoxic and Hypoxic HEK-293 Cells

The gel image of Figure 1C highlights significant differences in the copurified, potential CA IX interactors under normoxic and hypoxic conditions, with the affinity-purified material from the latter one being clearly more abundant. Each gel lane was cut into 21 slices for nLC-ESI-LIT-MS/MS-based protein identification. Results from each analysis are reported in Supporting Information Table S1. In particular, 29 (112 spectra), 45 (427 spectra), and 72 (286 spectra) proteins were identified in the normoxic, hypoxic, and mock samples, respectively. Table 1 summarizes the putative interacting partners of human CA IX, which were identified by subtracting data obtained for each gel slice (Figure 1C, lanes $\mathrm{N}$ and $\mathrm{H}$ ) with the corresponding ones from the mock sample. To further investigate physical and functional association of the 25 potential CA IX-binding partners, their list was submitted to the STRING database of protein interactions ${ }^{27}$ (Figure 2A). CA IX interactors identified from normoxic cells comprise the mitochondrial ATP synthase 
Table 1. CA IX Protein Ligands Identified under Normoxic and Hypoxic Conditions ${ }^{a}$

\begin{tabular}{|c|c|c|c|}
\hline accession & description & normoxic & hypoxic \\
\hline Q16790 & $\begin{array}{l}\text { carbonic anhydrase 9, CA9 } \\
\text { [CAH9_HUMAN] }\end{array}$ & X (bait) & X (bait) \\
\hline Q86VP6 & $\begin{array}{l}\text { Cullin-associated NEDD8-dissociated } \\
\text { protein 1, CAND1 [CAND1_HUMAN] }\end{array}$ & $\mathrm{X}$ & $\mathrm{X}$ \\
\hline Q9UN86 & $\begin{array}{l}\text { Ras GTPase-activating protein-binding } \\
\text { protein 2, G3BP2 [G3BP2_HUMAN] }\end{array}$ & $\mathrm{X}$ & \\
\hline P25705 & $\begin{array}{l}\text { ATP synthase subunit alpha, } \\
\text { mitochondrial, ATP5A1 } \\
\text { [ATPA_HUMAN] }\end{array}$ & $\mathrm{X}$ & \\
\hline P06576 & $\begin{array}{l}\text { ATP synthase subunit beta, mitochondrial, } \\
\text { ATP5B [ATPB_HUMAN] }\end{array}$ & $\mathrm{X}$ & \\
\hline Q9Y3I0 & $\begin{array}{l}\text { UPF0027 protein C22orf28, C22orf28 } \\
\text { [CV028_HUMAN] }\end{array}$ & $\mathrm{X}$ & $\mathrm{X}$ \\
\hline P46782 & $\begin{array}{l}\text { 40S ribosomal protein S5, RPS5 } \\
\text { [RS5_HUMAN] }\end{array}$ & $\mathrm{X}$ & $\mathrm{X}$ \\
\hline O75155 & $\begin{array}{l}\text { Cullin-associated NEDD8-dissociated } \\
\text { protein 2, CAND2 [CAND2_HUMAN] }\end{array}$ & & $\mathrm{X}$ \\
\hline Q13085 & $\begin{array}{l}\text { acetyl-CoA carboxylase 1, ACACA } \\
\text { [ACACA_HUMAN] }\end{array}$ & & $\mathrm{X}$ \\
\hline Q96P70 & importin-9, IPO9 [IPO9_HUMAN] & & $\mathrm{X}$ \\
\hline Q8TEX9 & importin-4, IPO4 [IPO4_HUMAN] & & $\mathrm{X}$ \\
\hline 000410 & importin-5, IPO5 [IPO5_HUMAN] & & $\mathrm{X}$ \\
\hline O95373 & importin-7, IPO7 [IPO7_HUMAN] & & $\mathrm{X}$ \\
\hline P52292 & $\begin{array}{l}\text { importin subunit alpha-2, KPNA2 } \\
\text { [IMA2_HUMAN] }\end{array}$ & & $\mathrm{X}$ \\
\hline Q9HAV4 & exportin-5, XPO5 [XPO5_HUMAN] & & $\mathrm{X}$ \\
\hline $\mathrm{O} 43592$ & exportin-T, XPOT [XPOT_HUMAN] & & $\mathrm{X}$ \\
\hline P55060 & exportin-2, CSE1L [XPO2_HUMAN] & & $\mathrm{X}$ \\
\hline O14980 & exportin-1, XPO1 [XPO1_HUMAN] & & $\mathrm{X}$ \\
\hline Q9Y5L0 & $\begin{array}{l}\text { transportin-3, TNPO3 } \\
{[\text { TNPO3_HUMAN }]}\end{array}$ & & $\mathrm{X}$ \\
\hline Q92973 & $\begin{array}{l}\text { transportin-1, TNPO1 } \\
\text { [TNPO1_HUMAN] }\end{array}$ & & $\mathrm{X}$ \\
\hline Q9UBB4 & ataxin-10, ATXN10 [ATXN10_HUMAN] & & $\mathrm{X}$ \\
\hline P00918 & $\begin{array}{l}\text { carbonic anhydrase } 2, \mathrm{CA} 2 \\
{[\mathrm{CAH} 2 \text { HUMAN }]}\end{array}$ & & $\mathrm{X}$ \\
\hline Q7Z492 & $\begin{array}{l}\text { HEAT repeat-containing protein 3, } \\
\text { HEATR3 [HEATR3_HUMAN] }\end{array}$ & & $\mathrm{X}$ \\
\hline Q96ER3 & $\begin{array}{l}\text { protein SAAL1, SAAL1 } \\
\text { [SAAL1_HUMAN] }\end{array}$ & & $\mathrm{X}$ \\
\hline Q9Y5M8 & $\begin{array}{l}\text { signal recognition particle receptor subunit } \\
\text { beta, SRPRB [SRPRB_HUMAN] }\end{array}$ & & $\mathrm{X}$ \\
\hline P40939 & $\begin{array}{l}\text { trifunctional enzyme subunit alpha, } \\
\text { HADHA [ECHA_HUMAN] }\end{array}$ & & $\mathrm{X}$ \\
\hline
\end{tabular}

${ }^{a}$ Strep-tagged CA IX from transfected cells grown under both normoxic and hypoxic conditions, and mock-transfected cells were affinity-purified on separate Strep-tactin columns with their bound interactors and resolved by SDS-PAGE. Each gel lane was cut into 21 similar slices, which were then treated with trypsin and subjected to nLC-ESI-LIT-MS/MS analysis for protein identification. Results subtracted from mock data are shown. Supporting Information Table S1 reports the raw data for normoxic, hypoxic and mock gel slices.

$\alpha / \beta$ subunits (ATP5A1 and ATP5B), and Ras GTPaseactivating protein-binding protein 2 (G3BP2), a scaffold component for mRNA transport. This protein is linked via exportin $\mathrm{XPO}^{32}$ to the main network of CA IX-interacting proteins identified under hypoxia (Figure 2A). Interestingly, most of the proteins of this network belong to the nucleocytoplasmic transport machinery, including several members of the importin- $\alpha$ (KPNA2), $-\beta$ (IPO4, IPO5, IPO7, IPO9, TNPO1, TNPO3), and exportin (XPO1, XPO2/CSE1L, XPO5, XPOT) families. STRING also highlighted connection of the signal recognition particle receptor subunit $\beta$ (SRPRB) with the ribosomal protein RPS5 and the catalytic subunit of the tRNA-splicing ligase complex (C22orf28). The latter two CA IX interactors were also found under normoxia. Proteins not connected in the network included the acetyl-CoA carboxylase 1 enzyme (ACACA), the HEAT repeat-containing protein 3 (HEATR3), the mitochondrial trifunctional enzyme subunit alpha (HADHA), the protein SAAL1, and the cullinassociated NEDD8-dissociated proteins 2 and 1 (CAND2 and CAND1), the latter being also found under normoxic conditions.

To get more information on the CA IX interacting partners, the identified proteins were classified in the David database ${ }^{28,29}$ (Figure 2B). Besides the obvious descriptions related to nucleocytoplasmic transport of proteins and RNA and nuclear pore/ envelope localization, a striking feature of 13 out of the 25 identified proteins was their relationship to the family of the ARM and HEAT-repeat containing proteins. Members of this family are characterized by the presence in their structure of $\alpha$ helical domains (HEAT and ARM motif), which are generally known to mediate protein-protein interactions. ${ }^{33}$ Identified proteins with HEAT/ARM-repeats included members of the nucleo-cytoplasmic transport machinery and additional components, such as CAND1, CAND2, and HEATR3.

To confirm identified CA IX-binding partners, coprecipitation experiments were performed for representative proteins. Figure $3 \mathrm{~A}$ shows that XPO1, TNPO1, and CAND1 actually coprecipitated with Strep-tagged CA IX in transfected HEK293 cells. In agreement with the results obtained by proteomic analysis (Table 1), XPO1 and TNPO1 were only represented in immunoprecipitates from the hypoxic condition. On the contrary, although more abundantly represented in the sample from hypoxic cells, CAND1 was detected also under normoxia. Since Western blotting of the input samples clearly showed that endogenous XPO1, TNPO1, and CAND1 levels do not vary in hypoxia, it can be postulated that the increased levels of the endogenous proteins interacting with Strep-tagged CA IX may be dependent on the observed overproduction of the CA IX protein in hypoxic cells.

C-Terminal Region of CA IX Is Required for the Interaction with XPO1, TNPO1, and CAND1

Most of the proteins identified as CA IX-interacting partners are presumed to be intracellular. Thus, considering the membrane topology of CA IX, we assumed that these interactions could involve the $\mathrm{C}$-terminal, cytosolic region of the protein (a.a. 434-459). Thus, peptides reproducing the cytosolic portion of CA IX were used in pull-down assays with cellular lysates from normoxic and hypoxic HEK-293 cells. Surprisingly, these peptides were unable to capture endogenous XPO1, TNPO1, and CAND1 irrespective of their phosphorylation status (Figure 3B, lanes 3 and 4). However, with longer peptides, encompassing CA IX portion 418-459, interaction with endogenous XPO1, TNPO1, and CAND1 from both normoxic and hypoxic cells was observed (Figure 3B, lanes 5$7)$. It is noteworthy that peptides phosphorylated at residues T443 and Y449 (lanes 5-6) showed a more efficient binding than the nonphosphorylated counterpart (Figure 3B, lanes 7). The specificity of the binding was verified by a scrambled Cterminal sequence peptide (Figure 3B, lanes 2). These experiments defined the CA IX C-terminal region 418-459 as the minimal sequence required for protein interaction with endogenous XPO1, TNPO1, and CAND1. Surprisingly, this region encompasses part of the membrane-spanning sequence 


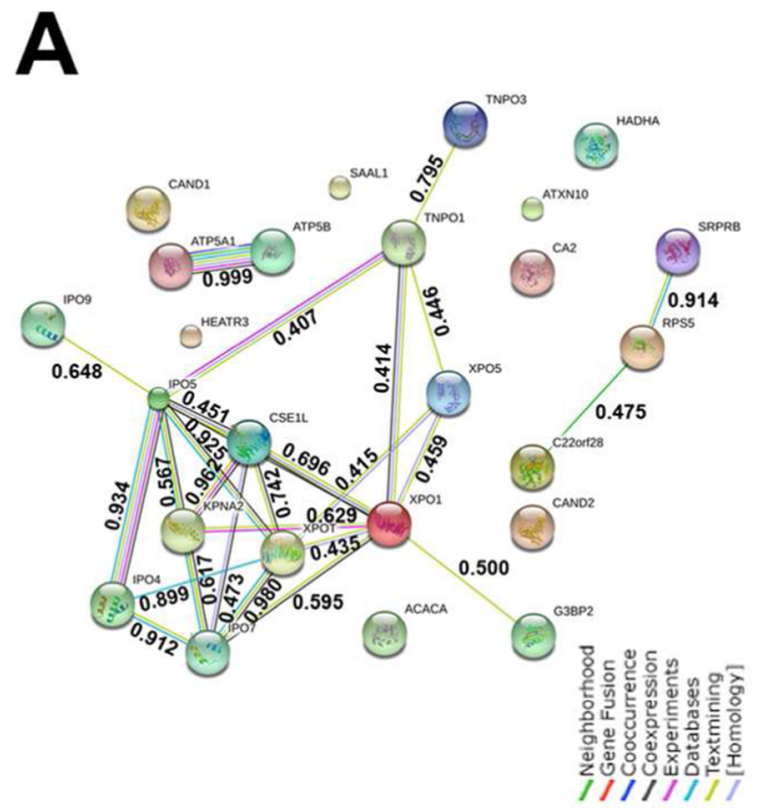

B

Figure 2. Bioinformatic characterization of the CA IX interactome. (A) Identified proteins were subjected to STRING analysis to reveal functional interaction between single components from the CA IX interactome. Proteins are connected by lines of different colors, according to the color code shown at the bottom. Values close to the lines report the confidence scores, as revealed by functional interaction analysis. (B) Annotation of the protein components from the CA IX interactome, as revealed by the DAVID platform, grouped the proteins indicated on top the figure according to the indicated descriptors for biological process (BP), cell compartment (CC), molecular function (MF), or protein family (INTERPRO).

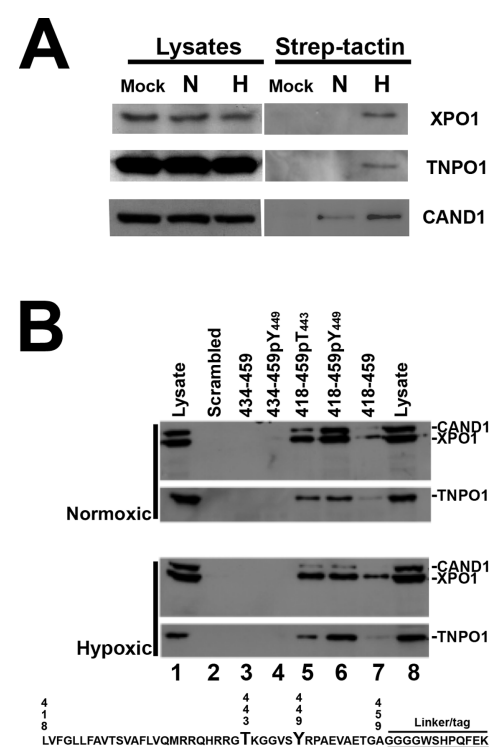

Figure 3. C-terminal sequence of CA IX is required for interaction with selected members of the CA IX interactome. (A) Coprecipitation of Strep-tagged CA IX with XPO1, TNPO1, and CAND1 proteins. HEK-293 cells were transfected with the empty vector (Mock) or the Strep-tagged CA IX expression vector, and incubated under normoxic $(\mathrm{N})$ or hypoxic $(\mathrm{H})$ conditions, as indicated. Cell lysates were purified on Strep-tactin resin and probed with the indicated antibodies to detect the endogenous XPO1, TNPO1, and CAND1 proteins. (B) Synthetic peptides corresponding to the amino acid sequences indicated on the top of the figure, or a peptide with a scrambled sequence, fused to a C-terminal Strep-tag were used in pull-down assays to evaluate the binding of the selected proteins from HEK-293 cells. Protein lysates were prepared from normoxic and hypoxic cells. Filters with the bound proteins were probed with the indicated antibodies to detect the XPO1, TNPO1, and CAND1 proteins. of CA IX, i.e., region 418-433. A bioinformatic analysis of this sequence highlighted the existence of both a hydrophobic region and a basic motif. The first one could putatively act as a Leu-rich nuclear export signal (NES) for interaction with exportins $^{34}$ (Supporting Information Figure S2), while the basic motif resembles a nuclear localization signal (NLS). ${ }^{35}$

CA IX Accumulates in the Nuclei of Hypoxic HEK-293 Cells and in Kidney Neoplasms

The reported data identify the nucleo-cytoplasmic trafficking machinery as a distinctive feature of the CA IX interactome. CA IX has been occasionally described as a nuclear protein in human cells. ${ }^{36-38}$ To evaluate whether endogenous CA IX participates in molecular complexes with the nucleocytoplasmic transport proteins in vivo, we performed coimmunoprecipitation analysis with XPO1, chosen as a representative member of CA IX interactome. Figure 4A shows that XPO1 is detected in complexes with CA IX in hypoxic HEK-293 cells, while the complex was undetectable in normoxic cells. Next, we evaluated CA IX subcellular localization in human cell lines by confocal immunofluorescence analysis (Supporting Information Figure S3). In colorectal carcinoma GEO cells, the strong expression of CA IX did correlate to prominent membrane staining and faint perinuclear or nuclear staining in selected cells. HEK-293, SH-SY5Y (neuroblastoma), and BJ-5ta (fibroblasts) exhibited a wider distribution of CA IX, characterized by a decreased membrane staining and an evident nuclear protein accumulation (Supporting Information Figure S3). We then explored in detail the CA IX and XPO1 subcellular distribution in HEK293 cells under normoxic and low-oxygen conditions. Figure 4B illustrates the staining for CA IX (green) and XPO1 (red); CA IX was expressed in several cellular compartments under normoxia. The diffuse, punctate CA IX staining (green, upper panel) finely delineated cellular shape, indicating limited membrane accumulation of the protein, in contrast with cells expressing high levels of endogenous CA IX (GEO, Supporting 
A

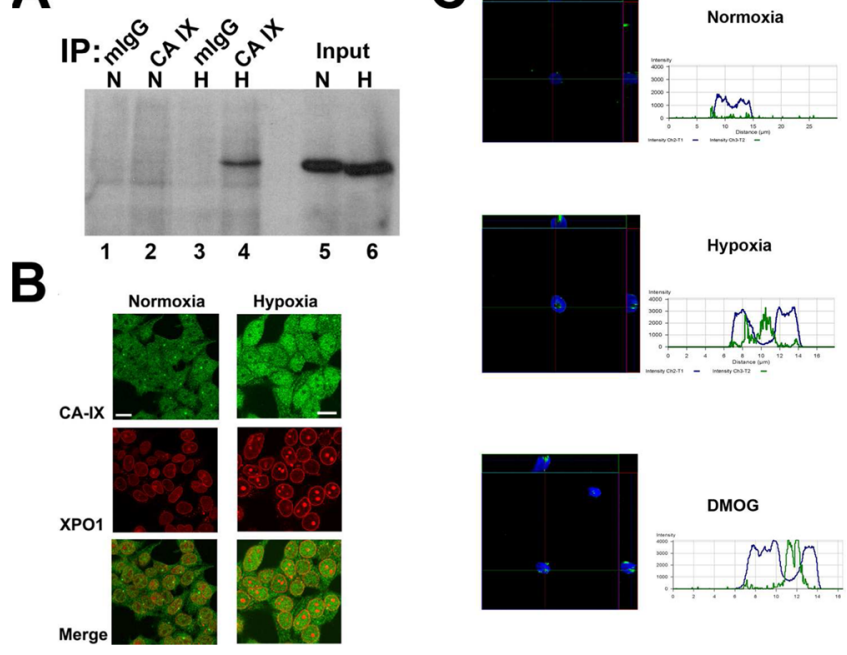

Figure 4. Analysis of endogenous CA IX/XPO1 protein complexes in normoxic and hypoxic cells. (A) Immunoprecipitates from normoxic (N, lanes 1,2) and hypoxic $(\mathrm{H}$, lanes 3, 4) HEK-293 cells were probed with XPO1 antibody. The extracts of lanes 1 and 3 were precipitated with control mouse IgGs, while the extracts of lanes 2 and 4 were precipitated with CA IX VII-20 monoclonal antibody. Input lysates were loaded in lanes 5 and 6. (B) Fixed cells from the indicated experimental conditions were permeabilized to detect intracellular endogenous CA IX (green) and XPO1 (red). Merged images are shown at the bottom of the figure. (C) Nuclei isolated from HEK-293CA IX cells were fixed on polylysine slides and stained with DAPI (blue) and with CA IX specific antibody (green). Merged images were converted to graphs representing the intensity profiles of DAPI and CA IX-related signals across the nuclei.

Information Figure S3) or ectopically expressed strep-tagged CA IX (transfected HEK293, Figure 1B), where the membrane staining was intense. The dispersed, homogeneous intracellular staining of normoxic cells was often interrupted at nucleoli. The latter feature became more evident in the red channel (middle panel) and in the merged image (lower panel), where nuclear membranes are highlighted by the perinuclear and in some cases nucleolar XPO1 staining. In addition, several cells showed bright fluorescence enrichment in close proximity to the nuclei, compatible with centrosome staining (Supporting Information Figure S4). Centrosome localization of CA IX was similarly found in hypoxic and normoxic cells. Thus, CA IX is diffusely represented in normoxic HEK-293 cells, and it seems highly enriched in centrosomes. Nuclear occurrence of CA IX increased in hypoxic cells (right column, Figure 4B). Such a feature can be appreciated by a major contrast of the stained nuclei, in comparison to the cytosolic signal. An additional feature of hypoxic cells was the striking redistribution of XPO1 to the nuclear envelope and to nucleoli. In fact, XPO1 did accumulate to low levels in most nucleoli of normoxic cells (Figures 4B and Supporting Information Figure S5), while the majority of nucleoli in hypoxic cells showed intense XPO1 staining (Figure 4B). Comparative analysis of the profiles of XPO1 and CA IX levels between normoxic and hypoxic conditions showed that CA IX is down-represented in the nucleoli of normoxic cells, compared to nuclear districts external to nucleoli (see profiles in Figure S6). On the contrary, the intensity of CA IX signals was significantly represented throughout the nuclear profile, including colocalization areas with XPO1 in nucleoli.
Nuclear localization of CA IX and its redistribution in nuclear compartments under hypoxia was also confirmed by confocal microscopy experiments on isolated nuclei from normoxic, hypoxic, and DMOG-treated HEK-293-CA9 cells constitutively expressing the full-length CA IX protein (Figure 4C), the latter being an example for a chemically induced hypoxia. Isolated nuclei were highlighted by DAPI. CA IX staining (green) appeared with a punctuate pattern in perinuclear compartments of normoxic cells; conversely, strong CA IX signals were easily appreciated in hypoxic cells, both in DAPI-stained nuclear compartments and in DAPI-excluded nucleoli. Under chemical hypoxia, an evident CA IX staining was also represented in the DAPI-excluded nucleoli. In all tested conditions, the isolated nuclei showed perinuclear enrichments of CA IX staining compatible with centrosome localization. Altogether, these results support the existence of a hypoxia-driven molecular mechanism regulating the increased expression of CA IX and its enriched presence in nuclear, nucleolar, and perinuclear compartments.

Given the observed nuclear localization of CA IX in HEK293 cells, as well as its functional interaction with the nucleocytoplasmic transport machinery, and with nuclear protein CAND1, we analyzed the distribution of CA IX in kidney neoplasms. Seven randomly selected renal cell carcinomas, clear cell type, were analyzed. Immunohistochemical detection of CA IX was clearly evident throughout the samples (Figure 5 for
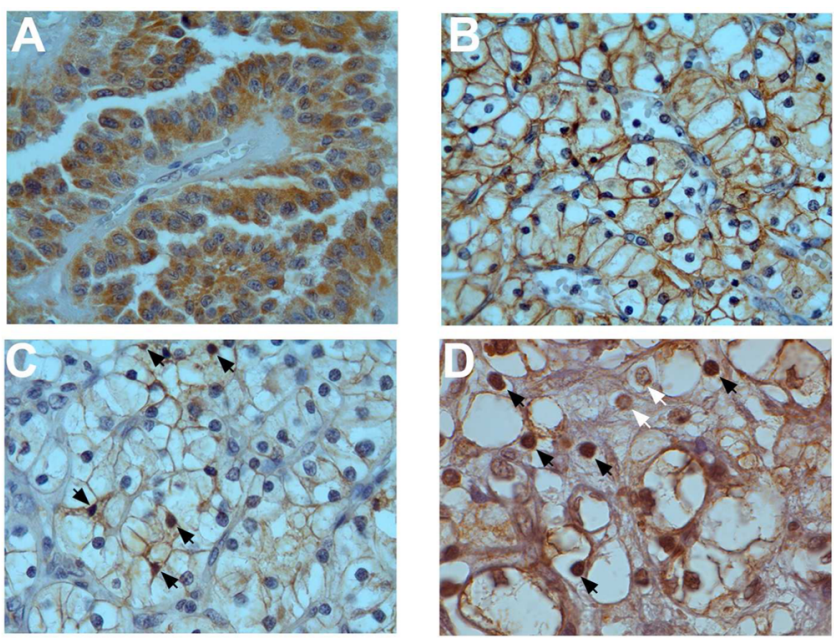

Figure 5. Immunohistochemical detection of CA IX in renal clear cell carcinoma. Shown are 4 representative specimens of renal clear cell carcinomas (A-D). The two cases at the bottom (C and D) show nuclear localization for CA IX. Black arrowheads denote a complete nuclear staining (C and D); white arrowheads show perinuclear staining.

representative samples). In particular, CA IX was mainly detected at the cell membrane and often codetected in the cytosol (Figure 5A-D). Two out of the seven specimens also showed a nuclear localization for CA IX (Figure 5C,D). Nuclear reactivity for CA IX was not associated with necrotic/ inflammatory areas, but rather with cancer tissue districts containing tightly linked neoplastic cells and a limited fibrovascular network, suggesting its possible relationship to physiological hypoxia. 
Down-Regulation of CAND1 Cells Reveals a Functional Interaction with CA IX

CAND1 is a nuclear protein involved in gene transcription and assembly of SCF ubiquitin ligase complexes. In the current paradigm, CAND1 binds to CUL1 in an inactive complex, inhibiting the assembly of the SCF complexes, thus preventing protein ubiquitylation and degradation. In order to evaluate whether CAND1 down-regulation is associated to CA IX protein stability, we generated stable pools of HEK-293 clones with decreased CAND1 expression via shRNA-mediated interference. The pools of cellular clones sh2555 and sh2562 actually showed down-regulated CAND1 protein levels, compared to cellular pools expressing a nonsilencing shRNA construct (shNS) (Figure 6). Despite similar levels of cellular

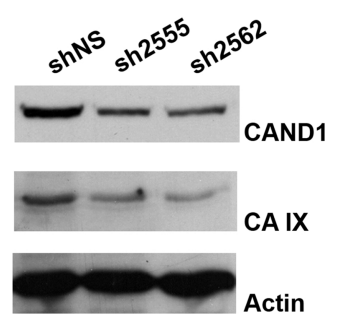

Figure 6. CAND1 down-regulation is associated with decreased CA IX levels in HEK-293 cells. Decreased CAND1 expression in the cellular pools of clones sh2555 and sh2562 was obtained after stable selection of cells expressing two shRNAs targeting CAND1 mRNAs. Shown are Western blot experiments performed to detect CAND1, CA IX, and actin levels in cellular pools, and in a pool expressing shNS.

actin, CA IX levels in the sh2555 and sh2562 clones clearly paralleled the decreased CAND1 expression. Thus, besides the occurrence of a physical interaction, CA IX and CAND1 show functional interaction that is required for stabilization of CA IX protein.

\section{DISCUSSION}

CA IX is a promising marker and target for anticancer therapy not only because of the hypoxia-induced cancer-related expression pattern, but also because of the active involvement in tumor biology. So far, the main attention has been paid to functional aspects of CA IX linked with its enzyme activity and plasma membrane position, namely to the ability to regulate $\mathrm{pH}$ and facilitate cell migration. However, our interactomic analysis disclosed a collection of CA IX partners belonging to different intracellular compartments, thus suggesting that CA IX might cross-talk with several signaling pathways and play additional roles inside tumor cells. The list of identified partners includes the signal recognition particle receptor subunit $\beta$ (SRPRB) mediating transit of nascent proteins through endoplasmic reticulum, mitochondrial ATPase subunits (ATP5A1, ATP5B) involved in respiratory chain, cytosolic Ras-GTPase activating $\mathrm{SH} 3$ domain-binding protein G3BP2 participating in Wnt signaling, ${ }^{39} 40 \mathrm{~S}$ ribosomal subunit protein RPS5 implicated in ribosome maturation, ${ }^{40}$ as well as cytoplasmic/nuclear proteins CAND1 and CAND2 regulating protein degradation and gene transcription. $^{41}$ It is noteworthy that the majority of the proteins interacting with CA IX represents components of the nucleo-cytoplasmic trafficking machinery, such as importin TNPO1 and exportin XPO1, which facilitate active import and export of proteins and/or mRNA through nuclear pores. These data strongly imply that CA IX is a protein with complex subcellular distribution, having the ability to transit through nuclear compartment. Although the nuclear localization would appear unusual for a cell surface protein, literature contains several paradigms of transmembrane receptors that enter the nucleus via the transportin-dependent pathway and function as nuclear signal transducers, such as c-Erb-B2, EGFR, FGFR, and CD44. ${ }^{42-44}$

Complex subcellular distribution including nuclear localization of CA IX was proven here to occur in living cells by confocal immunofluorescence analysis in several cell lines of different tissue origin. Since the cells were stained with the antibody against the extracellular portion of CA IX, it was apparently the full-length protein present in the nucleus, similarly to other receptors undergoing nuclear import. This is compatible with the ability of CA IX to internalize, a feature that appears essential for nuclear import of proteins derived from the cell surface. ${ }^{42-45}$ Importantly, hypoxic treatments led to increased CA IX protein accumulation within nuclei and its colocalization with XPO1 in nucleoli, where XPO1 itself was enriched as a consequence of limited oxygen availability. Accordingly, our biochemical data on the CA IX interaction with the components of the nucleo-cytoplasmic shuttling machinery, namely XPO1 and TNPO1, revealed an increased formation of protein complexes under low-oxygen conditions. The same effect was observed in case of coprecipitation of CAND1 protein with CA IX. Thus, coprecipitation data obtained with a Strep-tagged, ectopically expressed CA IX bait are fully compatible with the coimmunoprecipitation and immunofluorescence results obtained in nontransfected cells. Accordingly, it can be suggested that mammalian cells should present molecular mechanisms involved in the shuttling of CA IX toward, and from, the nucleus. The increased presence of CA IX in stable complexes with XPO1 in nucleoli may be then linked to a decreased nuclear export of the protein during hypoxia. We assume that these findings may reflect a higher abundance of CA IX under hypoxic conditions and/or the occurrence of specific hypoxia-related PTMs. Indeed, the in vitro association assays with synthetic peptides encompassing the C-terminal region of CA IX showed that phosphorylation at either T443 or Y439 residues results in a more efficient coprecipitation of CA IX with XPO1, TNPO1, and CAND1.

Interaction of CA IX with nucleo-cytoplasmic transport proteins enriched in the inner (XPO1) and outer (TNPO1) perinuclear compartments, and its participation in molecular complexes with CAND1 and CAND2, strongly suggests a role for CA IX within the nucleus and/or cytoplasm. In fact, CAND1 and CAND2 have been already associated with basal transcription ${ }^{46}$ and transcription activation; ${ }^{47}$ furthermore, both proteins participate in the assembly and function of the SCF ubiquitin ligase complexes, as negative regulators of protein degradation. ${ }^{48,49}$ The latter evidence is of particular relevance in light of our data that show the increased abundance of ectopically expressed CA IX in hypoxic cells. Since the production of ectopically expressed CA IX is driven by the CMV promoter devoid of obvious binding site for HIF1, the observed accumulation of the protein is likely attributable to post-transcriptional mechanisms in a low-oxygen environment. In line with this proposition, the CA IX levels were lower in cells with CAND1 suppressed by shRNA-mediated interference. Thus, it can be speculated that the functional interaction of CA IX with CAND1 may represent a positive feedback contributing to CA IX stabilization. 
Interactions of CA IX with XPO1 and TNPO1 can provide additional clues to understanding its potential intracellular roles. TNPO1 is a transport receptor that actively imports various proteins from the cytoplasm to the nucleus through nuclear pore complexes, and enables them to act in the nuclear compartment. The cargo proteins include transcription factors directly binding to DNA, cofactors of transcription operating through interactions with the transcriptional apparatus, mRNA binding proteins, and other components of the nuclear signaling network. This would imply a nuclear function for CA IX in signaling and transcription analogously to other imported transmembrane proteins, such as CD44 and EGFR. A hypothetical nuclear function for CA IX was already proposed on the basis of its ability to bind DNA in DNA-cellulose chromatography. ${ }^{2}$ Interestingly, sequence homology analysis against the human proteome revealed a similarity of the Cterminal region of CA IX with the $\mathrm{Zn}$ finger protein 784 (Supporting Information Figure S7). Bioinformatic analysis by different search algorithms confirmed the occurrence of a stretch of basic amino acids able to bind DNA. Nevertheless, it is also possible that nuclear CA IX functions through proteinprotein interactions rather than through direct binding to DNA. In any case, the experimental evidence for the CA IX role in nucleus is still missing, although this idea is supported by additional reports of nuclear/perinuclear CA IX staining in human tumor tissues and its association with poor prognosis. $^{37,38}$

On the other hand, XPO1 exportin mediates export of ribosomal proteins, mRNAs, and ribosomal subunits required for ribosomal biogenesis, and thereby contributes to control of translation. $^{50,51}$ It is quite conceivable that, through XPO1 binding, CA IX may affect assembly of the translational machinery, although such functional cooperation still remains to be explored. Nevertheless, in view of this assumption it seems logical that CA IX also interacts with the 40 S ribosomal subunit protein RPS5 contributing to ribosome maturation.

It is well-known that the nucleo-cytoplasmic transport machinery plays an important role in molecular responses to hypoxia through control of correct localization of the key components of hypoxia sensing and signal transduction, such as prolyl hydroxylases, pVHL tumor suppressor, subunits of HIF transcription complex, and their cofactors. ${ }^{52-54}$ Hypoxia also affects ribosome biogenesis and efficiency of translation. ${ }^{55}$ Moreover, hypoxia modulates protein degradation mechanisms. Thus, hypoxia intervenes with several pathways that include CA IX-interacting proteins. Since CA IX itself is strongly induced by hypoxia and exhibits increased stability and interaction potential in low oxygen conditions, it is also imaginable that CA IX may operate through its partners to affect hypoxic signaling and provide feedback mechanisms optimizing cellular adaptation to hypoxic stress. Our findings strongly indicate that this might occur via intracellular subpopulations of the full-length CA IX molecule, and particularly via its fraction trafficking to and from the nucleus.

In conclusion, the present study strongly supports the view that the CA IX-related scenario is much more complex than thought previously, both with respect to its subcellular distribution and to its potential functions in hypoxic cells. It appears that the canonical role of CA IX as $\mathrm{pH}$ and migration regulator at the plasma membrane is just a part of the complete story, and that additional, previously unexplored intracellular roles attributable to CA IX nuclear and/or cytoplasmic fractions should be taken into account. Given the current expectations for CA IX as a diagnostic and prognostic indicator, and as an attractive target for therapeutic intervention in tumors, it can be predicted that exploration of unanticipated CA IX functions can bring new opportunities for innovative anticancer strategies.

\section{ASSOCIATED CONTENT}

\section{Supporting Information}

Additional details and figures. This material is available free of charge via the Internet at http://pubs.acs.org.

\section{AUTHOR INFORMATION}

\section{Corresponding Author}

*E-mail: zambrano@unina.it (N.Z.), gdesimon@unina.it (G.D.S.).

\section{Author Contributions}

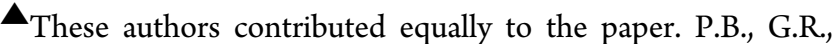
F.M., M.V., S.M.M., A.S., D.M., M.A., M.Z., and L.C. performed research; C.T.S., S.P., A.S., G.D.S., and N.Z. designed research; C.G., G.T., A.S., S.P., G.D.S., and N.Z. analyzed data; S.P., A.S., G.D.S., and N.Z. wrote the paper.

Notes

The authors declare no competing financial interest.

\section{ACKNOWLEDGMENTS}

Authors thank B. Crifò for generation of shRNA clones, A. Cannavo for cell treatments, and A. Usiello, G. Esposito, and T. Russo for critical discussions. This work was partly supported by funds from MIUR (PS 126-Ind) to CEINGE, from MIUR (PRIN2008 CCPKRP 002 and FIRB2008 RBNE08YFN3 003) to A.S., and from FP7 EU project (Metoxia) to C.T.S. and S.P. F.M. was a recipient of a doctoral position by Scuola Europea di Medicina Molecolare.

\section{ABBREVIATIONS}

CA, carbonic anhydrase; DAPI, 4',6-diamidino-2-phenylindole; IC, intracytoplasmic; nLC-ESI-LIT-MS/MS, nanoliquid chromatography coupled to electrospray-linear ion trap tandem mass spectrometry; PG, proteoglycan; PTM, post-translational modification; SCF, Skp, Cullin, F-box.

\section{REFERENCES}

(1) Supuran, C. T. Carbonic anhydrases: Novel therapeutic applications for inhibitors and activators. Nat. Rev. Drug Discov. 2008, 7 (2), 168-81.

(2) Pastorek, J.; Pastorekova, S.; Callebaut, I.; Mornon, J. P.; Zelnik, V.; Opavsky, R.; Zat'ovicova, M.; Liao, S.; Portetelle, D.; Stanbridge, E. J.; et al. Cloning and characterization of $\mathrm{MN}$, a human tumorassociated protein with a domain homologous to carbonic anhydrase and a putative helix-loop-helix DNA binding segment. Oncogene 1994, 9 (10), 2877-88.

(3) Opavsky, R.; Pastorekova, S.; Zelnik, V.; Gibadulinova, A.; Stanbridge, E. J.; Zavada, J.; Kettmann, R.; Pastorek, J. Human MN/ CA9 gene, a novel member of the carbonic anhydrase family: Structure and exon to protein domain relationships. Genomics 1996, 33 (3), $480-7$.

(4) Hilvo, M.; Baranauskiene, L.; Salzano, A. M.; Scaloni, A.; Matulis, D.; Innocenti, A.; Scozzafava, A.; Monti, S. M.; Di Fiore, A.; De Simone, G.; Lindfors, M.; Janis, J.; Valjakka, J.; Pastorekova, S.; Pastorek, J.; Kulomaa, M. S.; Nordlund, H. R.; Supuran, C. T.; Parkkila, S. Biochemical characterization of CA IX, one of the most active carbonic anhydrase isozymes. J. Biol. Chem. 2008, 283 (41), 27799-809. 
(5) Alterio, V.; Hilvo, M.; Di Fiore, A.; Supuran, C. T.; Pan, P.; Parkkila, S.; Scaloni, A.; Pastorek, J.; Pastorekova, S.; Pedone, C.; Scozzafava, A.; Monti, S. M.; De Simone, G. Crystal structure of the catalytic domain of the tumor-associated human carbonic anhydrase IX. Proc. Natl. Acad. Sci. U.S.A. 2009, 106 (38), 16233-8.

(6) Wykoff, C. C.; Beasley, N. J.; Watson, P. H.; Turner, K. J.; Pastorek, J.; Sibtain, A.; Wilson, G. D.; Turley, H.; Talks, K. L.; Maxwell, P. H.; Pugh, C. W.; Ratcliffe, P. J.; Harris, A. L. Hypoxiainducible expression of tumor-associated carbonic anhydrases. Cancer Res. 2000, 60 (24), 7075-83.

(7) Potter, C. P.; Harris, A. L. Diagnostic, prognostic and therapeutic implications of carbonic anhydrases in cancer. Br. J. Cancer 2003, 89 (1), 2-7.

(8) Svastova, E.; Hulikova, A.; Rafajova, M.; Zat'ovicova, M.; Gibadulinova, A.; Casini, A.; Cecchi, A.; Scozzafava, A.; Supuran, C. T.; Pastorek, J.; Pastorekova, S. Hypoxia activates the capacity of tumor-associated carbonic anhydrase IX to acidify extracellular $\mathrm{pH}$. FEBS Lett. 2004, 577 (3), 439-45.

(9) Svastova, E.; Witarski, W.; Csaderova, L.; Kosik, I.; Skvarkova, L.; Hulikova, A.; Zatovicova, M.; Barathova, M.; Kopacek, J.; Pastorek, J.; Pastorekova, S. Carbonic anhydrase IX interacts with bicarbonate transporters in lamellipodia and increases cell migration via its catalytic domain. J. Biol. Chem. 2012, 287 (5), 3392-402.

(10) Swietach, P.; Patiar, S.; Supuran, C. T.; Harris, A. L.; VaughanJones, R. D. The role of carbonic anhydrase 9 in regulating extracellular and intracellular ph in three-dimensional tumor cell growths. J. Biol. Chem. 2009, 284 (30), 20299-310.

(11) Pastorekova, S.; Parkkila, S.; Zavada, J. Tumor-associated carbonic anhydrases and their clinical significance. Adv. Clin. Chem. 2006, 42, 167-216.

(12) Monti, S. M.; Supuran, C. T.; De Simone, G. Carbonic anhydrase IX as a target for designing novel anticancer drugs. Curr. Med. Chem. 2012, 19 (6), 821-30.

(13) Pastorekova, S.; Zatovicova, M.; Pastorek, J. Cancer-associated carbonic anhydrases and their inhibition. Curr. Pharm. Des. 2008, 14 (7), 685-98.

(14) Svastova, E.; Zilka, N.; Zat'ovicova, M.; Gibadulinova, A.; Ciampor, F.; Pastorek, J.; Pastorekova, S. Carbonic anhydrase IX reduces E-cadherin-mediated adhesion of MDCK cells via interaction with beta-catenin. Exp. Cell Res. 2003, 290 (2), 332-45.

(15) Zavadova, Z.; Zavada, J. Carbonic anhydrase IX (CA IX) mediates tumor cell interactions with microenvironment. Oncol. Rep. 2005, 13 (5), 977-82.

(16) Zavada, J.; Zavadova, Z.; Pastorek, J.; Biesova, Z.; Jezek, J.; Velek, J. Human tumour-associated cell adhesion protein MN/CA IX: identification of M75 epitope and of the region mediating cell adhesion. Br. J. Cancer 2000, 82 (11), 1808-13.

(17) Hulikova, A.; Zatovicova, M.; Svastova, E.; Ditte, P.; Brasseur, R.; Kettmann, R.; Supuran, C. T.; Kopacek, J.; Pastorek, J.; Pastorekova, S. Intact intracellular tail is critical for proper functioning of the tumor-associated, hypoxia-regulated carbonic anhydrase IX. FEBS Lett. 2009, 583 (22), 3563-8.

(18) Ditte, P.; Dequiedt, F.; Svastova, E.; Hulikova, A.; OhradanovaRepic, A.; Zatovicova, M.; Csaderova, L.; Kopacek, J.; Supuran, C. T.; Pastorekova, S.; Pastorek, J. Phosphorylation of carbonic anhydrase IX controls its ability to mediate extracellular acidification in hypoxic tumors. Cancer Res. 2011, 71 (24), 7558-67.

(19) Dorai, T.; Sawczuk, I. S.; Pastorek, J.; Wiernik, P. H.; Dutcher, J. $\mathrm{P}$. The role of carbonic anhydrase IX overexpression in kidney cancer. Eur. J. Cancer 2005, 41 (18), 2935-47.

(20) Caratu, G.; Allegra, D.; Bimonte, M.; Schiattarella, G. G.; D’Ambrosio, C.; Scaloni, A.; Napolitano, M.; Russo, T.; Zambrano, N. Identification of the ligands of protein interaction domains through a functional approach. Mol. Cell. Proteomics 2007, 6 (2), 333-45.

(21) Shevchenko, A.; Wilm, M.; Vorm, O.; Mann, M. Mass spectrometric sequencing of proteins silver-stained polyacrylamide gels. Anal. Chem. 1996, 68 (5), 850-8.

(22) Gallo, G.; Renzone, G.; Alduina, R.; Stegmann, E.; Weber, T.; Lantz, A. E.; Thykaer, J.; Sangiorgi, F.; Scaloni, A.; Puglia, A. M.
Differential proteomic analysis reveals novel links between primary metabolism and antibiotic production in Amycolatopsis balhimycina. Proteomics 2010, 10 (7), 1336-58.

(23) Vitale, M.; Renzone, G.; Matsuda, S.; Scaloni, A.; D’Adamio, L.; Zambrano, N. Proteomic characterization of a mouse model of familial danish dementia. J. Biomed. Biotechnol. 2012, 728178.

(24) Picariello, G.; Ferranti, P.; Mamone, G.; Roepstorff, P.; Addeo, F. Identification of $\mathrm{N}$-linked glycoproteins in human milk by hydrophilic interaction liquid chromatography and mass spectrometry. Proteomics 2008, 8 (18), 3833-47.

(25) D’Ambrosio, C.; Arena, S.; Salzano, A. M.; Renzone, G.; Ledda, L.; Scaloni, A. A proteomic characterization of water buffalo milk fractions describing PTM of major species and the identification of minor components involved in nutrient delivery and defense against pathogens. Proteomics 2008, 8 (17), 3657-66.

(26) Arena, S.; Renzone, G.; Novi, G.; Paffetti, A.; Bernardini, G.; Santucci, A.; Scaloni, A. Modern proteomic methodologies for the characterization of lactosylation protein targets in milk. Proteomics 2010, 10 (19), 3414-34.

(27) Szklarczyk, D.; Franceschini, A.; Kuhn, M.; Simonovic, M.; Roth, A.; Minguez, P.; Doerks, T.; Stark, M.; Muller, J.; Bork, P.; Jensen, L. J.; von Mering, C. The STRING database in 2011: functional interaction networks of proteins, globally integrated and scored. Nucleic Acids Res. 2011, 39 (Database issue), D561-8.

(28) Huang da, W.; Sherman, B. T.; Lempicki, R. A. Systematic and integrative analysis of large gene lists using DAVID bioinformatics resources. Nat. Protoc. 2009, 4 (1), 44-57.

(29) Huang da, W.; Sherman, B. T.; Lempicki, R. A. Bioinformatics enrichment tools: paths toward the comprehensive functional analysis of large gene lists. Nucleic Acids Res. 2009, 37 (1), 1-13.

(30) Zat'ovicova, M.; Tarabkova, K.; Svastova, E.; Gibadulinova, A.; Mucha, V.; Jakubickova, L.; Biesova, Z.; Rafajova, M.; Ortova Gut, M.; Parkkila, S.; Parkkila, A. K.; Waheed, A.; Sly, W. S.; Horak, I.; Pastorek, J.; Pastorekova, S. Monoclonal antibodies generated in carbonic anhydrase IX-deficient mice recognize different domains of tumourassociated hypoxia-induced carbonic anhydrase IX. J. Immunol. Methods 2003, 282 (1-2), 117-34.

(31) Fields, G. B.; Noble, R. L. Solid phase peptide synthesis utilizing 9-fluorenylmethoxycarbonyl amino acids. Int. J. Pept. Protein Res. 1990, 35 (3), 161-214.

(32) Prigent, M.; Barlat, I.; Langen, H.; Dargemont, C. IkappaBalpha and IkappaBalpha /NF-kappa B complexes are retained in the cytoplasm through interaction with a novel partner, RasGAP SH3binding protein 2. J. Biol. Chem. 2000, 275 (46), 36441-9.

(33) Andrade, M. A.; Petosa, C.; O’Donoghue, S. I.; Muller, C. W.; Bork, P. Comparison of ARM and HEAT protein repeats. J. Mol. Biol. 2001, 309 (1), 1-18.

(34) Henderson, B. R.; Eleftheriou, A. A comparison of the activity, sequence specificity, and CRM1-dependence of different nuclear export signals. Exp. Cell Res. 2000, 256 (1), 213-24.

(35) Lee, B. J.; Cansizoglu, A. E.; Suel, K. E.; Louis, T. H.; Zhang, Z.; Chook, Y. M. Rules for nuclear localization sequence recognition by karyopherin beta 2. Cell 2006, 126 (3), 543-58.

(36) Pastorekova, S.; Zavadova, Z.; Kostal, M.; Babusikova, O.; Zavada, J. A novel quasi-viral agent, MaTu, is a two-component system. Virology 1992, 187 (2), 620-6.

(37) Swinson, D. E.; Jones, J. L.; Richardson, D.; Wykoff, C.; Turley, H.; Pastorek, J.; Taub, N.; Harris, A. L.; O’Byrne, K. J. Carbonic anhydrase IX expression, a novel surrogate marker of tumor hypoxia, is associated with a poor prognosis in non-small-cell lung cancer. J. Clin. Oncol. 2003, 21 (3), 473-82.

(38) Dungwa, J. V.; Hunt, L. P.; Ramani, P. Carbonic anhydrase IX up-regulation is associated with adverse clinicopathologic and biologic factors in neuroblastomas. Hum. Pathol. 2012, 43 (10), 1651-1660.

(39) Bikkavilli, R. K.; Malbon, C. C. Wnt3a-stimulated LRP6 phosphorylation is dependent upon arginine methylation of G3BP2. J. Cell Sci. 2012, 125 (10), 2446-56.

(40) Campbell, M. G.; Karbstein, K. Protein-protein interactions within late pre-40S ribosomes. PLoS One 2011, 6 (1), e16194. 
(41) Lee, J. E.; Sweredoski, M. J.; Graham, R. L.; Kolawa, N. J.; Smith, G. T.; Hess, S.; Deshaies, R. J. The steady-state repertoire of human SCF ubiquitin ligase complexes does not require ongoing Nedd8 conjugation. Mol. Cell. Proteomics 2011, 10 (5), M1 10006460.

(42) Giri, D. K.; Ali-Seyed, M.; Li, L. Y.; Lee, D. F.; Ling, P.; Bartholomeusz, G.; Wang, S. C.; Hung, M. C. Endosomal transport of ErbB-2: mechanism for nuclear entry of the cell surface receptor. Mol. Cell. Biol. 2005, 25 (24), 11005-18.

(43) Bryant, D. M.; Stow, J. L. Nuclear translocation of cell-surface receptors: lessons from fibroblast growth factor. Traffic 2005, 6 (10), 947-54.

(44) Janiszewska, M.; De Vito, C.; Le Bitoux, M. A.; Fusco, C.; Stamenkovic, I. Transportin regulates nuclear import of CD44. J. Biol. Chem. 2010, 285 (40), 30548-57.

(45) Zatovicova, M.; Jelenska, L.; Hulikova, A.; Csaderova, L.; Ditte, Z.; Ditte, P.; Goliasova, T.; Pastorek, J.; Pastorekova, S. Carbonic anhydrase IX as an anticancer therapy target: Preclinical evaluation of internalizing monoclonal antibody directed to catalytic domain. Curr. Pharm. Des. 2010, 16 (29), 3255-63.

(46) Makino, Y.; Yogosawa, S.; Kayukawa, K.; Coin, F.; Egly, J. M.; Wang, Z.; Roeder, R. G.; Yamamoto, K.; Muramatsu, M.; Tamura, T. TATA-Binding protein-interacting protein 120, TIP120, stimulates three classes of eukaryotic transcription via a unique mechanism. Mol. Cell. Biol. 1999, 19 (12), 7951-60.

(47) Aoki, T.; Okada, N.; Wakamatsu, T.; Tamura, T. A. TBPinteracting protein $120 \mathrm{~B}$, which is induced in relation to myogenesis, binds to NOT3. Biochem. Biophys. Res. Commun. 2002, 296 (5), 1097103.

(48) Duda, D. M.; Scott, D. C.; Calabrese, M. F.; Zimmerman, E. S.; Zheng, N.; Schulman, B. A. Structural regulation of cullin-RING ubiquitin ligase complexes. Curr. Opin. Struct. Biol. 2011, 21 (2), 25764.

(49) Shiraishi, S.; Zhou, C.; Aoki, T.; Sato, N.; Chiba, T.; Tanaka, K.; Yoshida, S.; Nabeshima, Y.; Tamura, T. A. TBP-interacting protein 120B (TIP120B)/cullin-associated and neddylation-dissociated 2 (CAND2) inhibits SCF-dependent ubiquitination of myogenin and accelerates myogenic differentiation. J. Biol. Chem. 2007, 282 (12), 9017-28.

(50) Turner, J. G.; Dawson, J.; Sullivan, D. M. Nuclear export of proteins and drug resistance in cancer. Biochem. Pharmacol. 2012, 83 (8), 1021-32.

(51) Zemp, I.; Kutay, U. Nuclear export and cytoplasmic maturation of ribosomal subunits. FEBS Lett. 2007, 581 (15), 2783-93.

(52) Groulx, I.; Lee, S. Oxygen-dependent ubiquitination and degradation of hypoxia-inducible factor requires nuclear-cytoplasmic trafficking of the von Hippel-Lindau tumor suppressor protein. Mol. Cell. Biol. 2002, 22 (15), 5319-36.

(53) Steinhoff, A.; Pientka, F. K.; Mockel, S.; Kettelhake, A.; Hartmann, E.; Kohler, M.; Depping, R. Cellular oxygen sensing: Importins and exportins are mediators of intracellular localisation of prolyl-4-hydroxylases PHD1 and PHD2. Biochem. Biophys. Res. Commun. 2009, 387 (4), 705-11.

(54) Mylonis, I.; Chachami, G.; Samiotaki, M.; Panayotou, G.; Paraskeva, E.; Kalousi, A.; Georgatsou, E.; Bonanou, S.; Simos, G. Identification of MAPK phosphorylation sites and their role in the localization and activity of hypoxia-inducible factor-1alpha. J. Biol. Chem. 2006, 281 (44), 33095-106.

(55) Koritzinsky, M.; Wouters, B. G. Hypoxia and regulation of messenger RNA translation. Methods Enzymol. 2007, 435, 247-73. 